\title{
Solution Dosage Form Category
}

National Cancer Institute

\section{Source}

National Cancer Institute. Solution Dosage Form Category. NCI Thesaurus. Code C154598.

A type of liquid pharmaceutical dose form consisting of one or more substances dissolved in, or miscible with, an appropriate solvent, forming a single-phase liquid. 